\title{
Effects of diet cycling on weight loss, fat loss and resting energy expenditure in women
}

\author{
Julie Y Kresta*, Mike Byrd, Jonathan M Oliver, Claire Canon, Michelle Mardock, Sunday Simbo, Yanghoon Jung, \\ Majid Koozehchian, Deepesh Khanna, Brittanie Lockard, Ryan Dalton, Han K Kim, Chris Rasmussen, \\ Richard B Kreider
}

From International Society of Sports Nutrition; 7th Annual ISSN Conference and Expo

Clearwater Beach, FL, USA. 24-26 June 2010

\section{Background}

The Curves fitness program involves a 30-minute circuit training program. Women interested in losing weight can also follow a weight management program. The most recent version of the weight management program involves cycling between periods of moderate calorie restriction $(1,200-1,500 \mathrm{kcals} / \mathrm{d})$ followed by periods of higher caloric intake $(2,200 \mathrm{kcals} / \mathrm{d})$ in an attempt to prevent long term reductions in resting energy expenditure (REE). The purpose of this preliminary study was to examine the efficacy of this exercise and diet cycling program approach on weight loss, fat loss, and REE.

\section{Methods}

Thirty-six overweight and sedentary women $(35 \pm 8 \mathrm{yr}$; $200 \pm 42 \mathrm{lbs} ; 43 \pm 4 \%$ fat, $33.4 \pm 6 \mathrm{~kg} / \mathrm{m}^{2}$ ) were assigned to a high carbohydrate $(\mathrm{HC}, \mathrm{n}=17)$ or high protein (HP, $\mathrm{n}=19$ ) diet group. During the first 30 -days, subjects consumed 1,200 kcals/d for 1 -wk followed by ingesting $1,500 \mathrm{kcals} / \mathrm{d}$ for 3-wks. Subjects then followed a 2,200 $\mathrm{kcals} / \mathrm{d}$ maintenance diet for 4-wks before repeating the 30-day diet. Diets were 45:30:25\% or 30:45:25\% CHO: PRO:F for the HC and HP groups, respectively. Subjects also participated in the Curves circuit training program (30-minute hydraulic resistance exercises interspersed with recovery floor calisthenics performed at 30-second intervals) $3-\mathrm{d} / \mathrm{wk}$ and walked briskly for $30-\mathrm{min} 3-\mathrm{d} / \mathrm{wk}$. Data were analyzed by MANOVA with repeated measures and are presented as means \pm SD changes from baseline after 1, 2, 3, 4 and 5 months for the $\mathrm{HC}$ and HP groups, respectively.

Exercise and Sport Nutrition Laboratory, Texas A\&M University, College Station, TX, USA

\section{Results}

There were significant time effects at each monthly time point compared to baseline for decreases in weight $(-5.1$ $\pm 4.5,-6.9 \pm 5.5,-8.9 \pm 7.1,-10.0 \pm 8.4,-10.7 \pm 9.6 \mathrm{lbs}, \mathrm{p}=0.001)$, fat mass $(-3.8 \pm 3.5,-5.5 \pm 4.2,-6.2 \pm 4.4,-7.8 \pm 5.8$, and $-7.7 \pm 6.7$ lbs, $\mathrm{p}=0.001)$ and percent body fat $(-0.9 \pm 1.7,-1.5 \pm 1.8,-1.5$ $\pm 1.8,-2.2 \pm 2.2,-2.0 \pm 2.5 \%, \mathrm{p}<0.01)$. There were no significant diet effects seen between HP and $\mathrm{HC}$ groups for changes in overall weight $(-7.3 \pm 1.3 ;-6.5 \pm 1.3 \mathrm{lbs}, \mathrm{p}=0.65)$ or fat mass $(-5.3 \pm 0.8 ;-5.1 \pm 0.9 \mathrm{lbs}, \mathrm{p}=0.85)$. In terms of REE, there were no significant differences between diet groups in overall changes in REE $(-50.8 \pm 32.5 ;-52.7 \pm 34.4 \mathrm{kcals} / \mathrm{d}$, $\mathrm{p}=0.97)$ or changes in the REE over the 5 month program $(-52.2 \pm 165,-73.3 \pm 214,-63.5 \pm 217,-64.9 \pm 203,-56.2 \pm 189$ $\mathrm{kcals} / \mathrm{d}, \mathrm{p}=0.49)$ indicating that subjects were able to lose weight without significant reductions in REE.

\section{Conclusion}

Short-term diet cycling during a weight loss and exercise program may be an effective way to promote weight loss without associated reductions in REE. In addition, preliminary findings indicate that the HP and $\mathrm{HC}$ diet approaches employed were equally effective.

\section{Acknowledgement}

We would like to thank Jean Jitomir, Monica Serra, Jen Moreillon, Erika Deike, Geoffrey Hudson, and Mike Greenwood who assisted in data collection on the first cohort of subjects that participated in this study when the ESNL was located at Baylor University. This study was supported by Curves International, Waco, TX.

Published: 15 September 2010

doi:10.1186/1550-2783-7-S1-P21

Cite this article as: Kresta et al.: Effects of diet cycling on weight loss,

fat loss and resting energy expenditure in women. Journal of the International Society of Sports Nutrition 2010 7(Suppl 1):P21. 